\title{
Aryl hydrocarbon receptor activation maintained the intestinal epithelial barrier function through Notch1 dependent signaling pathway
}

\author{
ZHONGZE LIU, LIANGZI LI, WEIGANG CHEN, QIMENG WANG, WEIDONG XIAO, \\ YUANHANG MA, BAIFA SHENG, XIANG LI, LIHUA SUN, MIN YU and HUA YANG \\ Department of General Surgery, Xinqiao Hospital, The Third Military Medical University, Chongqing 400037, P.R. China
}

Received September 8, 2016; Accepted December 15, 2017

DOI: $10.3892 / \mathrm{ijmm} .2017 .3341$

\begin{abstract}
Intestinal ischemia/reperfusion (I/R) induces disruption of the intestinal barrier function. Aryl hydrocarbon receptor (AhR) has a vital role in maintaining the intestinal barrier function. However, the precise mechanism by which AhR maintains intestinal barrier function remains unclear. Notch1 signaling is downstream of AhR, and has also been reported to have a role in the development of tight junctions (TJs) and maintenance of intestinal homeostasis. Therefore, we hypothesized that AhR activation may attenuate the intestinal barrier dysfunction through increased activation of Notch1 signaling. Adult C57BL/6J mice were divided into three groups: Sham, I/R and I/R + 6-formylindolo(3,2-b) carbazole (Ficz) groups. Mice were sacrificed after I/R for $6 \mathrm{~h}$ and the intestine was harvested for histological examination, mRNA and protein content analysis, and mucosal permeability investigation. Additionally, a hypoxic Caco-2 cell culture model was used to evaluate the role of AhR-Notch1 signaling in the development of TJs and epithelial permeability in vitro. The AhR-Notch1 signaling components and TJ proteins were assessed by reverse transcription-quantitative polymerase chain reaction, western blotting, immunohistochemistry or immunofluorescence staining. Epithelial permeability was detected by transepithelium electrical resistance. The data demonstrated that Ficz significantly attenuated the intestinal tissue damage and the disrupted distribution of TJs, increased the expression of TJ proteins, reversed the decrease in TER and upregulated epithelial Notch1 signaling following intestinal I/R in vivo and hypoxia in vitro. Furthermore, inhibition of Notch1 signaling by $\mathrm{N}$-[N-(3,5-difluorophenacetyl)-L-alanyl]-S-phenylglycine t-butyl ester (inhibitor of Notch signaling) counteracted
\end{abstract}

Correspondence to: Professor Hua Yang, Department of General Surgery, Xinqiao Hospital, The Third Military Medical University, 83 Xinqiao Main Street, Chongqing 400037, P.R. China

E-mail: hwbyang@126.com

Key words: aryl hydrocarbon receptor, Notch, tight junction, ischemia/reperfusion, intestinal barrier function the effects of Ficz on the development of TJs in hypoxic Caco- 2 cells. In conclusion, AhR activation ameliorated epithelial barrier dysfunction following intestinal $I / R$ and hypoxia through upregulation of Notch1 signaling, which suggests that AhR may be a potential pharmaceutical agent to combat this condition.

\section{Introduction}

Intestinal ischemia/reperfusion (I/R) can be a fatal syndrome that occurs in a variety of important clinical scenarios, including major trauma, septic shock, and small bowel or liver transplantation (1). Acute intestinal I/R results in the disruption of intestinal barrier function, initiating the systemic inflammatory response syndrome, and finally leading to the multiple organ dysfunction syndrome, with high mortality rate $(2,3)$. Intestinal epithelial cells (IECs) are the most dominant sectors of the intestinal epithelial barrier (IEB). Tight junctions (TJs), which are composed of a cluster of transmembrane proteins [including tight junction protein 1 (ZO-1), occludin and claudins] and firmly connect adjacent epithelial cells, regulate the permeability of ions, water and nutrients via the paracellular pathway, establish cell polarity and are a primary determinant of IEB function (4). Recent studies have demonstrated that disruption of the expression and distribution of TJs caused by intestinal $\mathrm{I} / \mathrm{R}$ are responsible for hyperpermeability and intestinal IEB dysfunction in several animal models $(5,6)$. The precise molecular mechanisms of dynamic regulation of TJs under this pathophysiology remain unclear.

Aryl hydrocarbon receptor (AhR), a ligand-dependent transcription factor widely expressed in the cytosol of various cells and tissues, is involved in numerous biological processes, including cell proliferation, apoptosis, differentiation and the inflammatory response (7-10). Upon binding with ligands, such as 6-formylindolo(3,2-b)carbazole (Ficz), activated AhR translocates from the cytosol to the nucleus and dimerizes with aryl hydrocarbon receptor nuclear translocator (ARNT) to initiate the transcription of target genes, such as cytochrome P450 (CYP1A1), which contains functional AhR responsive elements (AhREs). Recently, studies have focused on the protective role of AhR activation in immune cells in the gut. Increasing evidence has demonstrated that AhR activation 
ameliorated mucosal injury in several animal models of experimental colitis $(11,12)$, whereas AhR-deficient mice developed more severe colitis than their wild-type counterparts (13-15). Although it has been previously reported that AhR activation by MG132 alleviated liver injury caused by intestinal I/R (16), to the best of our knowledge, no study has investigated the effects of AhR activation by Ficz on intestinal structure and barrier function following intestinal $\mathrm{I} / \mathrm{R}$ in vivo and under hypoxia in vitro.

Previous studies have demonstrated that deficiency of Notch1 signaling is involved in the disrupted distribution of TJs and increased permeability, while restoration of epithelial Notch1 activation is associated with normal barrier function in a recombination activating 1 (RAG1)-adoptive transfer model of colitis in vivo, and in the Caco-2 cell line in vitro $(17,18)$. Additionally, Notch1 signaling is also involved in the regeneration and adaptation of intestinal epithelium in acute and chronic pathological conditions, including I/R (19,20). All these results indicate that Notch1 signaling may be important for the maintenance of intestinal renewal and barrier function.

Studies also confirmed that Notch1 has several AhREs in its promotersandisinducedby 2,3,7,8-tetrachlorodibenzo-p-dioxin (TCDD; an exogenous ligand of AhR) and Ficz in hepatocytes, intestinal innate lymphocytes (ILCs) and bone marrow-derived dendritic cells (BMDCs) (21-23). Notably, activated Notch signaling promotes the production of certain unknown endogenous stimulators of AhR in a concanavalin A-induced hepatitis model (24). As AhR and Notch1 are expressed in the intestinal epithelium, and Notch1 signaling has been confirmed to have a crucial role in maintaining the intestinal homeostasis under different pathological conditions including I/R (17-20), the positive feedback loop of AhR-Notch1 signaling may be a underlying mechanism in regulation of the intestinal homeostasis under pathological conditions. In the present study, we hypothesized that AhR activation by Ficz may maintain the epithelial architecture and barrier function via upregulation of Notch1 signaling in a mouse model of acute intestinal I/R and cell model of hypoxia.

\section{Materials and methods}

Animals. The 6-8 week-old male C57BL/6 mice weighing 20-23 g were purchased from the Laboratory Animal Center, the Third Military Medical University (Chongqing, China). All animals were housed in plastic boxes with ad libitum access to standard rodent chow and water at $20-22^{\circ} \mathrm{C}$ with a constant 12-h light/dark cycle. An initial adaptation period of 1 week was allowed prior to the experiments. Mice were randomly divided into three groups: Sham operation (sham; $n=7$ ), I/R $(n=7), I / R+F i c z$ (Enzo Life Sciences, Inc., Farmingdale, NY, USA) ( $n=7)$. All animal experiments and protocols were approved by the Animal Care and Use Committee of the Third Military Medical University. All efforts were made to minimize the suffering of the mice.

Intestinal I/R and treatment. All animals were fasted for $12 \mathrm{~h}$ and were free to drink water prior to surgery. All experimental protocols were administrated under aseptic conditions. All mice were intraperitoneally injected with $40 \mathrm{mg} / \mathrm{kg}$ pentobarbital as anesthesia and then subjected to aseptic laparotomy at medioventral line. For I/R and I/R + Ficz groups, the superior mesenteric artery (SMA) of each mouse was occluded with a non-traumatic microvascular clamp for $20 \mathrm{~min}$. The mice in sham group received the same operation except occlusion of the SMA. Then, all the clamps were removed and the incisions were sutured layer-by-layer. With normal saline (NS) vehicle, Ficz ( $1 \mu \mathrm{g} / \mathrm{mouse})$ were administered intraperitoneally to the mice in $\mathrm{I} / \mathrm{R}+$ Ficz group to activate AhR. Equal volumes of NS were administered by the same route to the mice in other groups as control. Following the surgery, all mice were given free access to food and water and sacrificed at $6 \mathrm{~h}$ after reperfusion. The small bowel of each mouse was quickly excised and processed for histological assessment and IEC isolation.

IECs isolation. IECs isolation was performed according to our previous study (25). Briefly, the whole small intestine was removed and placed in tissue culture media [RPMI-1640, with $10 \%$ fetal calf serum (both from Gibco; Thermo Fisher Scientific, Inc., Waltham, MA, USA)]. The section was cut into 5-mm pieces, washed in an isolation buffer [190 mg ethylenediaminetetraacetic acid (EDTA) and $80 \mathrm{mg}$ dichlorodiphenyltrichloroethane dissolved in $500 \mathrm{ml}$ phosphate-buffered saline (PBS)], and incubated in the same buffer with continuous brisk stirring at $37^{\circ} \mathrm{C}$ for $30 \mathrm{~min}$. The supernatant was filtered rapidly through a glass wool column. Following centrifugation at $400 \mathrm{x} \mathrm{g}$ at $4^{\circ} \mathrm{C}$ for $5 \mathrm{~min}$, the pellets were purified in $40 \%$ isotonic Percoll (GE Healthcare Life Sciences, Logan, UT, USA) and cells recovered in the suspension were collected for RNA or protein extraction.

Histological examination. Segments of treated jejunum were harvested, fixed in $4 \%$ paraformaldehyde at $4{ }^{\circ} \mathrm{C}$ overnight for histological evaluation. Tissues were embedded in paraffin, cut into 5- $\mu \mathrm{m}$ sections and dehydrated successively in 70, 80, 95 and $100 \%$ gradient ethanol at room temperature for $5 \mathrm{~min}$ for hematoxylin and eosin (H\&E) staining. The sections were stained with hematoxylin ( $1 \mathrm{~g} / \mathrm{l})$ for $5 \mathrm{~min}$ and eosin $(5 \mathrm{~g} / \mathrm{l})$ for $3 \mathrm{~min}$ both at room temperature. The intestinal mucosal injury was assessed under a light microscope (Leica Microsystems $\mathrm{GmbH}$, Wetzlar, Germany) at x200 magnification in accordance with the Chiu's intestinal mucosa injury criteria (26) and graded from 0 to 5 .

Immunohistochemistry staining. Tissues were fixed with $4 \%$ paraformaldehyde at $4^{\circ} \mathrm{C}$ overnight, embedded in the paraffin, sliced into $5-\mu \mathrm{m}$ sections, dehydrated successively in $70,80,95$ and $100 \%$ in the gradient ethanol at room temperature for $5 \mathrm{~min}$, treated with $0.3 \%$ hydrogen peroxide in methanol at room temperature for $20 \mathrm{~min}$. Subsequently, the sections were soaked in citrate buffer $(\mathrm{pH} \mathrm{6.0)}$ and heated by microwave for $20 \mathrm{~min}$ for antigen retrieval. The sections were incubated with anti-AhR antibody (ab2770; 1:200; Abcam, Cambridge, UK), anti-Notch1 antibody (D1E11; 3608; 1:200; Cell Signaling Technology, Inc., Danvers, MA, USA), anti-ZO-1 (21773-1-AP; 1:200) and anti-occludin (13409-1AP; 1:200) antibodies (ProteinTech Group, Inc., Chicago, IL, USA) at $4^{\circ} \mathrm{C}$ overnight and then blocking with $5 \%$ bovine serum albumin (BSA; SA1020; ready to use; Wuhan Boster Biological Technology Ltd., Wuhan, China) at room temperature for $20 \mathrm{~min}$. These sections were successively incubated 
with biotinylated goat anti-mouse and rabbit secondary antibody (SA1020, ready to use) and avidin-biotin complex (SA1020; ready to use) (both from Wuhan Boster Biological Technology Ltd.) at $37^{\circ} \mathrm{C}$ for $20 \mathrm{~min}$. The peroxidase activities were detected by diaminobenzidine $(0.5 \mathrm{mg} / \mathrm{ml})$ staining at room temperature for $20 \mathrm{sec}$. Following counterstaining with hematoxylin $(1 \mathrm{~g} / \mathrm{l})$ at room temperature for $1 \mathrm{~min}$, histological evaluation was performed under a light microscope at $\mathrm{x} 400$ magnification.

Detection of intestinal permeability. The transepithelium electrical resistance (TER; $\Omega / \mathrm{cm}^{2}$ ), which indicates tissue viability and IEB function (27), was determined according to Ohm's law. The permeability of the small bowel was assessed by TER. Tissues were placed in modified Ussing chambers (Physiologic Instruments, Inc., San Diego, CA, USA) and bathed with $5 \mathrm{ml} \mathrm{Krebs}$ buffer $(110.0 \mathrm{mM} \mathrm{NaCl}, 3.0 \mathrm{mM}$ $\mathrm{CaCl}_{2}, 5.5 \mathrm{mM} \mathrm{KCl}, 1.4 \mathrm{mM} \mathrm{KH}_{2} \mathrm{PO}_{4}, 29.0 \mathrm{mM} \mathrm{NaHCO}_{3}$, $1.2 \mathrm{mM} \mathrm{MgCl} 2, \mathrm{pH}$ 7.4) on mucosal and serosal sides. The buffer was continuously oxygenated with $5 \% \mathrm{CO}_{2}$ in $\mathrm{O}_{2}$ and maintained at $37^{\circ} \mathrm{C}$ by water-jacketed reservoirs. After a $20 \mathrm{~min}$ period of equilibration, the detections were performed for up to $90 \mathrm{~min}$ in Ussing chambers. TER was calculated by the injected short-circuit current and spontaneous potential difference.

Cell culture and treatment. The human Caco-2 colon carcinoma cell line was obtained from American Type Culture Collection (Manassas, VA, USA) and maintained in a culture media composed of minimum essential medium (MEM; Gibco; Thermo Fisher Scientific, Inc.) supplemented with 15\% fetal bovine serum (Gibco; Thermo Fisher Scientific, Inc.), $1 \%$ non-essential amino acids (HyClone; GE Healthcare Life Sciences, Logan, UT, USA), $100 \mathrm{U} / \mathrm{ml}$ penicillin, and $100 \mu \mathrm{g} / \mathrm{ml}$ streptomycin (Beyotime Institute of Biotechnology, Haimen, China) at $37^{\circ} \mathrm{C}$ in a $5 \% \mathrm{CO}_{2}$ humidified incubator and subcultured by partial digestion with $0.25 \%$ trypsin and $0.53 \mathrm{mM}$ EDTA in PBS without $\mathrm{Ca}^{2+}$ or $\mathrm{Mg}^{2+}$. The culture medium was changed every other day.

The in vitro hypoxic environment was used to simulate in vivo $\mathrm{I} / \mathrm{R}$ condition. Caco-2 cells were seeded on 6-well plates at a density of $1 \times 10^{6}$ cells/well. Once the monolayers reached $70-80 \%$ confluence, they were cultured with serum-free MEM basic media overnight and then exposed to hypoxic $(\mathrm{Hx})$ environments $\left(1 \% \mathrm{O}_{2}, 5 \% \mathrm{CO}_{2}\right.$ and $94 \% \mathrm{~N}_{2}$, and $90 \%$ humidity) at $37^{\circ} \mathrm{C}$ for $0,6,12$ or 24 h, with or without Ficz (Enzo Life Sciences, Inc.) or $\mathrm{N}$-[N-(3,5-difluorophenacetyl)-L-alanyl]-S-phenylglycine t-butyl ester (DAPT; Santa Cruz Biotechnology, Inc., Dallas, TX, USA) at appropriate concentrations. The controls were incubated under normoxic (Nx) conditions.

Immunofluorescence analysis. The confluent Caco-2 monolayers cultured on glass bottom cell culture dish were treated as described above and then rinsed three times in PBS, fixed with $4 \%$ paraformaldehyde at $4^{\circ} \mathrm{C}$ for $20 \mathrm{~min}$, and then permeabilized using $0.2 \%$ Triton X-100 in PBS at room temperature for $30 \mathrm{~min}$. Following blocking in 5\% BSA at room temperature for $2 \mathrm{~h}$, monolayers were incubated with mouse anti-AhR antibody (ab2770; 1:50; Abcam), rabbit anti-Notch1 intracel- lular domain (NICD1) antibody (D1E11; 3608; 1:50; Cell Signaling Technology, Inc.), rabbit anti-ZO-1 (21773-1-AP; 1:50) and rabbit anti-occludin (13409-1-AP; 1:50) antibodies (both from ProteinTech) at $4^{\circ} \mathrm{C}$ overnight. Monolayers were then washed three times and incubated with fluorescein isothiocyanate-conjugated goat anti-mouse (A0568; 1:300) or Cy3-conjugated goat anti-rabbit (A0516; 1:300) secondary antibodies (Beyotime Institute of Biotechnology) for $1 \mathrm{~h}$. DAPI ( $1 \mathrm{mg} / \mathrm{ml}$; Invitrogen; Thermo Fisher Scientific, Inc.) was used for nuclear staining at room temperature for $10 \mathrm{~min}$. Following extensive rinsing, the images were captured using a laser scanning fluorescence microscopy (TCS SP5; Leica Microsystems GmbH).

Measurement of TER. The integrity of the confluent Caco-2 cells was assessed by measuring the TER. Caco- 2 cells were seeded on Millicell filters $\left(0.33 \mathrm{~cm}^{2}\right.$ area, $0.4-\mu \mathrm{m}$ pore diameter and $6.5 \mathrm{~mm}$ diameter) at a density of $0.5 \times 10^{5} \mathrm{cells} / \mathrm{cm}^{2}$ as monolayers and experiments were performed when confluent. The TER of the treated monolayers was detected using a Millicell ERS-2 voltohmmeter (EMD Millipore, Billerica, MA, USA) according to Ohm's law. TER $\left(\Omega / \mathrm{cm}^{2}\right)=($ total resistance - blank resistance) $(\Omega) /$ area $\left(\mathrm{cm}^{2}\right)$.

Reverse transcription-quantitative polymerase chain reaction ( $R T-q P C R)$ analysis. Total RNA extracted by isothiocyanate/chloroform extraction using TRIzol (Life Technologies; Thermo Fisher Scientific, Inc.) was reversed into cDNA using a PrimeScript RT reagent kit (Takara Bio, Inc., Otsu, Japan). The amplified cDNA was utilized for the template DNA and performed with specific primers for PCR assay. The RT reaction was performed in thermocycler (Bio-Rad Laboratories, Inc., Hercules, CA, USA) at $42^{\circ} \mathrm{C}$ for $2 \mathrm{~min}, 37^{\circ} \mathrm{C}$ for $15 \mathrm{~min}$, and $85^{\circ} \mathrm{C}$ for $5 \mathrm{sec}$. Subsequently, The average quantification cycle threshold $(\mathrm{Ct})$ of the triplicate samples was calculated as the quantity of gene pruduct and the relative mRNA expression levels were analyzed by $2^{-\Delta \Delta \mathrm{Ct}}$ method (28) by Rotor-Gene Q series software (Qiagen GmbH, Hilden, Germany) in accordance with the standard PCR conditions $\left(94^{\circ} \mathrm{C}\right.$ for $10 \mathrm{~min}$, and 40 cycles of $45 \mathrm{sec}$ at $94^{\circ} \mathrm{C}, 30 \mathrm{sec}$ at $59^{\circ} \mathrm{C}, 45 \mathrm{sec}$ at $72^{\circ} \mathrm{C}$ ). In the present study, the following primers were used: $\beta$-actin (mouse) forward 5'-CTTCTTTGC AGCTCCTTCGTT-3' and reverse 5'-AGGAGTCCTTCTGAC CCATTC-3'; CYP1A1 (mouse) forward 5'-CCAAGAGCT GCTCAGCATAG-3' and reverse 5'-GGCATCCAGGGAAGA GTTAG-3'; Notch1 (mouse) forward 5'-ATGTCAATGTTC GAGGACCAG-3' and reverse 5'-TCACTGTTGCCTGTC TCAAG-3'; hes family bHLH transcription factor 1 (HES-1; mouse) forward 5'-CCAGCCAGTGTCAACACGA-3' and reverse 5'-AATGCCGGGAGCTATCTTTCT-3'. Data were collected and analyzed with Rotor-Gene Q series software (Qiagen $\mathrm{GmbH}$ ).

Western blotting. Proteins were extracted from the murine IECs and Caco-2 monolayers in cold radioimmunoprecipitation assay buffer [PBS, $1 \%$ NP-40, $0.5 \%$ sodium deoxycholate, $0.1 \% \mathrm{SDS}, 1 \mu \mathrm{g} / \mathrm{ml}$ phenylmethanesulfonyl fluoride, $1.0 \mathrm{mM}$ sodium orthovanadate and $1 \mathrm{X}$ mammalian protease inhibitor cocktail (Sigma-Aldrich; Merck KGaA, Darmstadt, Germany)]. Following centrifugation at $14,462 \times \mathrm{g}$ at $4^{\circ} \mathrm{C}$ 


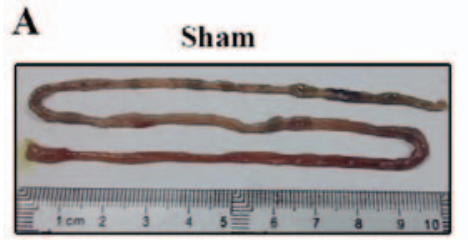

B Sham

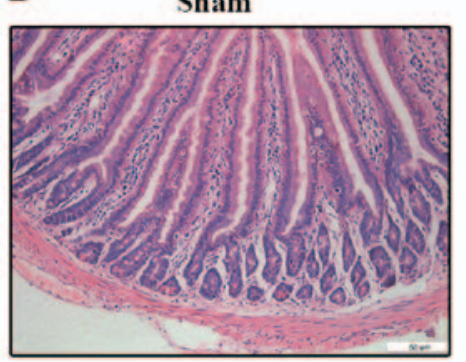

C

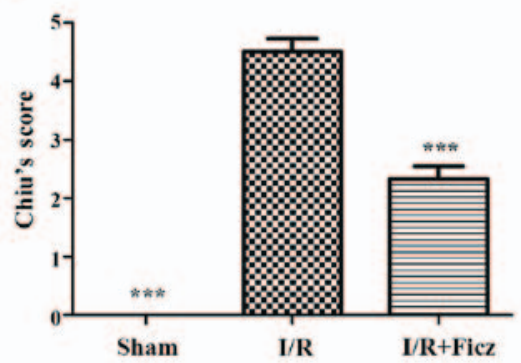

$\mathbf{I} / \mathbf{R}$

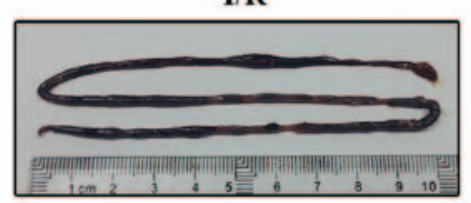

$\mathbf{I} / \mathbf{R}$

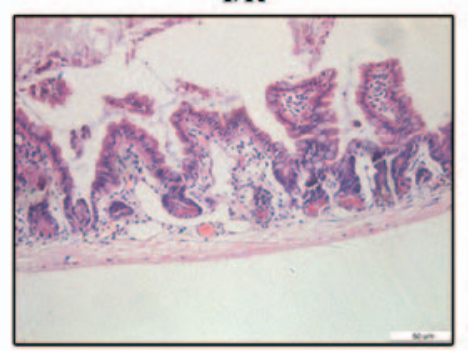

I/R+Ficz

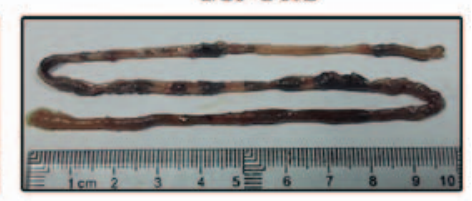

I/R+Ficz

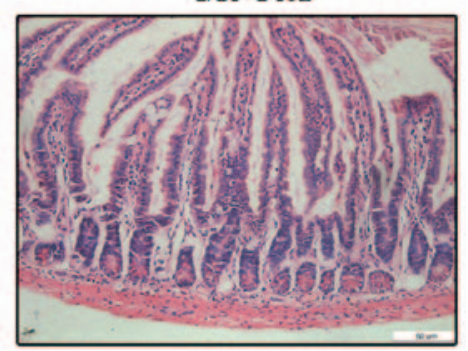

D

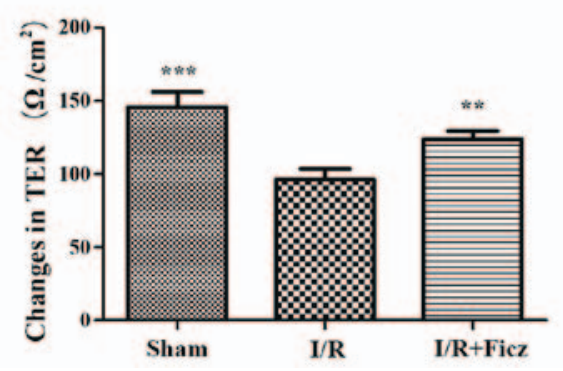

Figure 1. Ficz alleviates the mucosal damage and hyperpermeability induced by murine I/R. (A) Representative images of small intestine harvested from three groups (sham, I/R and I/R + Ficz). (B) Hematoxylin and eosin staining of the gut tissues captured by inverted microscope (original magnification, x200; scale bar, $50 \mu \mathrm{m} ; \mathrm{n}=5$ ). (C) Graphic representation of Chiu's score according to (B). (D) Epithelial permeability was assessed by TER, which was detected using Ussing chambers. Data are presented as the mean \pm standard deviation. ${ }^{* * *} \mathrm{P}<0.01,{ }^{* * * *} \mathrm{P}<0.001 \mathrm{vs}$. I/R group, $\mathrm{n}=3$. Ficz, 6-formylindolo(3,2-b)carbazole; $\mathrm{I} / \mathrm{R}$, ischemia/reperfusion; TER, transepithelium electrical resistance.

for $15 \mathrm{~min}$, proteins were quantified by the Bradford method utilizing the bicinchoninic acid assay reagent (Beyotime Institute of Biotechnology). Equal volumes of proteins were loaded into $10 \%$ SDS-polyacrylamide gels and transferred onto $0.2-\mu \mathrm{m}$ polyvinylidene difluoride-Plus membranes. Following blocking with $5 \% \mathrm{BSA}$ at room temperature for $1 \mathrm{~h}$, the membranes were incubated at $4^{\circ} \mathrm{C}$ overnight with the following primary antibodies: anti-GAPDH antibody (sc-47724; 1:1,000; Santa Cruz Biotechnology, Inc.), anti-AhR antibody (ab2770; 1:500; Abcam), anti-CYP1A1 antibody (13241-1-AP; 1:500; ProteinTech), anti-NICD1 antibody (D1E11; 3608; 1:500; Cell Signaling Technology, Inc.), anti-HES-1 antibody (sc-166378; 1:500; Santa Cruz Biotechnology, Inc.), anti-ZO-1 (21773-1-AP; 1:500) and anti-occludin (13409-1-AP; 1:500) antibodies (both from ProteinTech). Following washing, the membranes were incubated with horseradish peroxidase-conjugated goat antimouse secondary antibody (BA1051; 1:5,000; Wuhan Boster Biological Technology Ltd.) or horseradish peroxidase-conjugated goat anti-rabbit secondary antibody (BA1055; 1:5,000; Wuhan Boster Biological Technology Ltd.) for $1 \mathrm{~h}$ at room temperature and visualized with an enhanced chemiluminescence system (EMD Millipore) and imaging system (Kodak Gel Logic 4000R Imaging System; Carestream Health, Inc., Rochester, NY, USA). Protein expression was normalized to that of GAPDH and the densitometry of the western blot bandings was analyzed using Image J software (Version 1.50i; National institutes of Health,Bethesda, MD, USA).
Statistical analysis. Data are presented as the mean \pm standard deviation. Differences among groups were evaluated by analysis of one-way analysis of variance with Student-Newman-Keuls test using SPSS statistical software package (version 13.0; SPSS, Inc., Chicago, IL, USA). $\mathrm{P}<0.05$ was considered to indicate a statistically significant difference.

\section{Results}

Ficz ameliorates the mucosal histological lesions and loss of intestinal barrier function following $I / R$ in mice. It was demonstrated by our previous study that intestinal I/R resulted in the intestinal barrier dysfunction in mice, as indicated by the decreased TER and the increased paracellular permeability (6). Since AhR activation by MG132 has been reported to alleviate the liver injury caused by intestinal I/R in rats (16), to investigate into the effect of AhR activation by Ficz on I/R-induced intestinal barrier dysfunction, the morphological structure of intestinal mucosa and epithelial permeability were detected in the current study. The representative images of the small intestine demonstrated that edema and hyperemia were clear in the I/R group, but rarely observed in the sham or IR + Ficz group (Fig. 1A). The histological examination was performed on the basis of criteria proposed by Chiu et al (26). The typical histologic features exhibited in the I/R and $\mathrm{I} / \mathrm{R}+$ Ficz groups were characterized by shortening of the villi, shedding of the epithelium, and prominent mucosal and muco- 
A
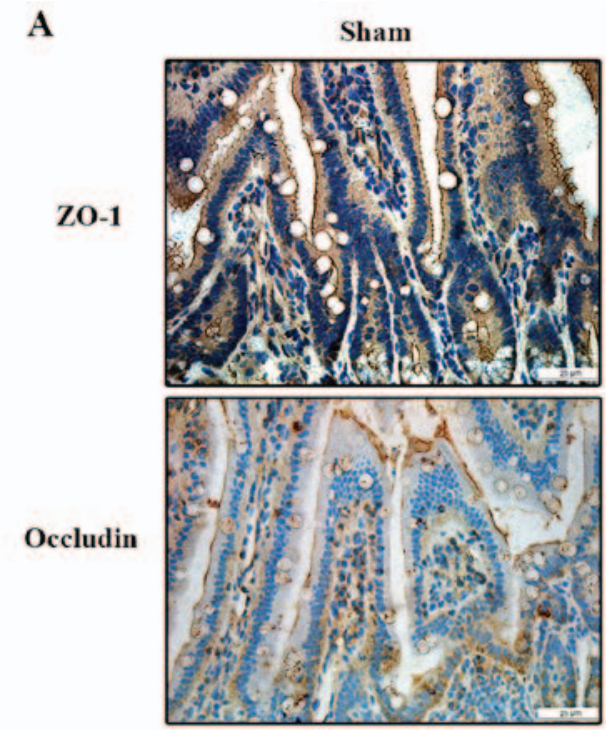

B

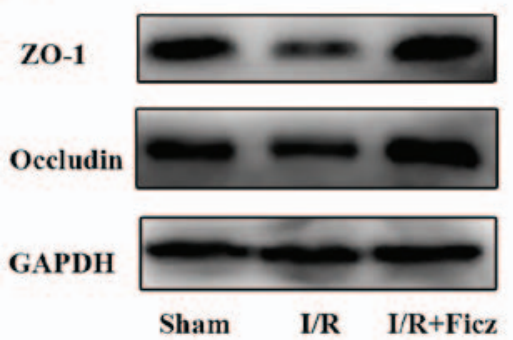

C
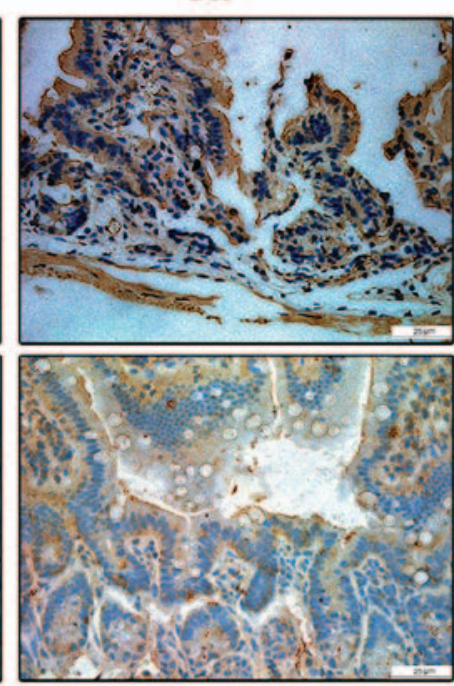

I/R+Ficz
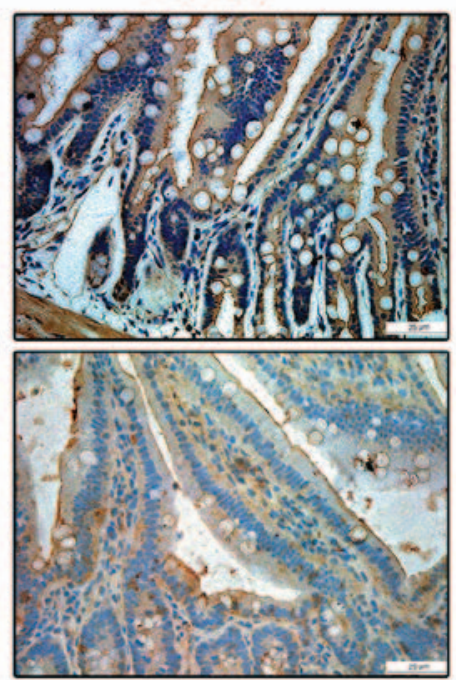

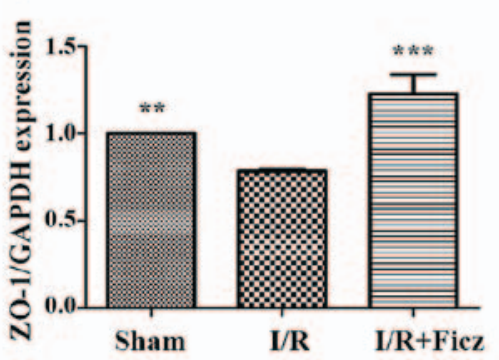

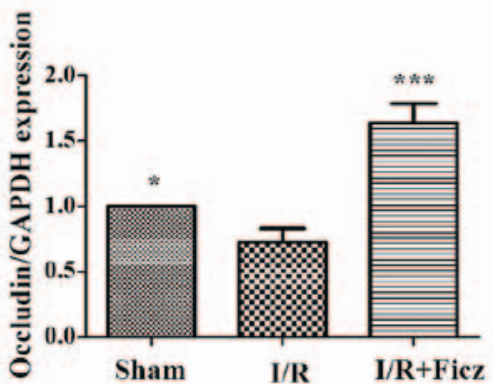

Figure 2. Ficz maintains the integrity and sufficient quantity of tight junctions (ZO-1 and occludin) following murine I/R. (A) Expression and distribution of ZO-1 and occludin in three groups (sham, I/R and I/R + Ficz) were detected by immunohistochemistry staining (original magnification, $\mathrm{x} 400$; scale bar, $25 \mu \mathrm{m}$; $\mathrm{n}=3$ ). (B) Western blotting of ZO-1, occludin and GAPDH protein levels. (C) Relative expression of proteins in (B), GAPDH was used to verify equivalent loading. Data are presented as the mean \pm standard deviation. ${ }^{*} \mathrm{P}<0.05,{ }^{* *} \mathrm{P}<0.01,{ }^{* * *} \mathrm{P}<0.001$ vs. I/R group; $\mathrm{n}=3$. I/R, ischemia/reperfusion; Ficz, 6-formylindolo(3,2-b)carbazole; ZO-1, tight junction protein 1.

dermal immune cell infiltration (Fig. 1B). The results indicated that Ficz significantly improved the intestinal morphological lesions (scored 2.33 \pm 0.52 ), compared with those in the I/R

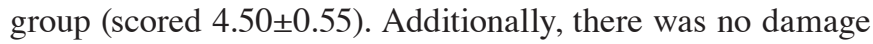
in the jejunal mucosa in the sham group (scored 0; Fig. 1C). To further confirm the effects of Ficz on the maintenance of IEB function, TER was detected by Ussing chambers as the permeability of intestinal mucosa (27). Intestinal I/R caused a markedly decrease in TER $\left(96.07 \pm 7.53 \Omega / \mathrm{cm}^{2}\right)$ compared with the sham group $\left(145.4 \pm 10.79 \Omega / \mathrm{cm}^{2}\right)$. Ficz partially rescued the reduction in TER following intestinal I/R $\left(123.8 \pm 5.56 \Omega / \mathrm{cm}^{2}\right)$, though the TER remained lower than that in the sham group (Fig. 1D). These findings revealed that Ficz significantly attenuated the I/R-induced epithelial barrier dysfunction.

Ficz maintains the expression and distribution of TJ proteins following intestinal $I / R$. Our previous study confirmed that intestinal I/R lead to the disrupted distribution of TJs (5). To determine the effects of AhR activation on the development of TJs following I/R in mice, immunohistochemistry staining and western blotting were performed to detect the distribution and expression of TJ proteins, including ZO-1 and occludin. The results demonstrated that, in the sham group, $\mathrm{ZO}-1$ and occludin were located at the apex of the villous enterocytes in a chicken wire-like pattern. The distribution of ZO-1 and occludin was clearly disrupted following intestinal I/R (Fig. 2A). The ZO-1 and occludin protein expression in the small bowel following intestinal I/R was also significantly decreased compared with the sham group (Fig. 2B and C). However, Ficz ameliorated the altered distribution of ZO-1 and occludin following intestinal I/R, and normal structures reappeared and were maintained (Fig. 2A). Ficz also markedly increased the protein expression of ZO-1 and occludin following intestinal I/R compared with the I/R group (Fig. $2 \mathrm{~B}$ and $\mathrm{C}$ ). These results suggested that AhR activation by Ficz has an important effect on in the development of TJs following intestinal I/R.

Activation of AhR by Ficz upregulates epithelial Notchl signaling following intestinal $I / R$ in mice. Previous studies have reported that $\mathrm{AhR}$ activation by endogenous and exogenous ligands can induce the expression of Notch1 gene expression (21-23), and AhR and Notch1 signaling have important roles in maintaining intestinal epithelial homeostasis; thus, the effects of I/R and Ficz on the expression and activity of AhR-Notch1 signaling pathway were investigated in the current study. As CYP1A1 is part of the AhR gene battery (29) and is induced through AhR signaling, CYP1A1 induction was used as an index to assess the activity of the AhR signaling pathway (30). NICD1 and HES-1 expression 
A

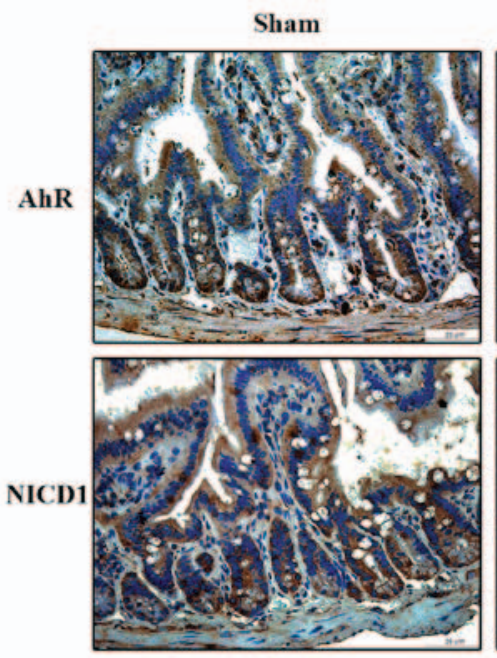

I/R

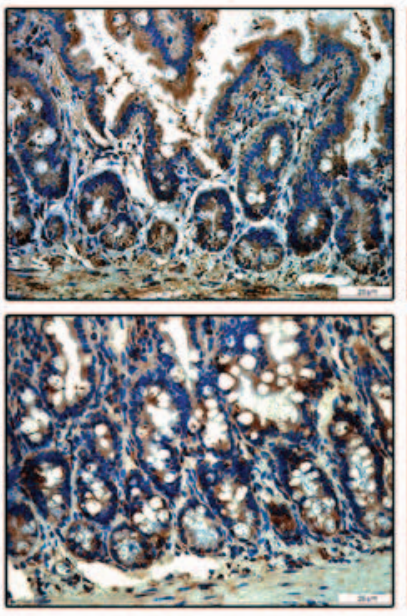

I/R+Ficz

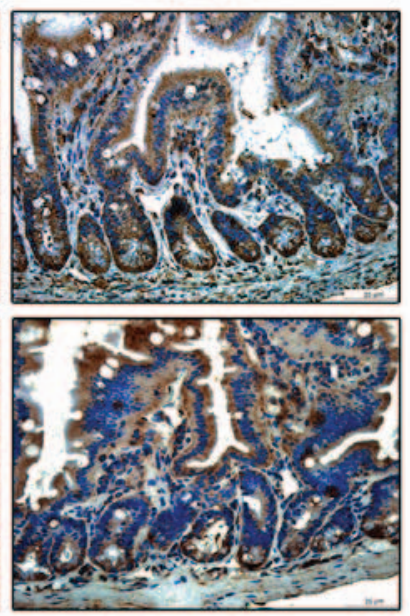

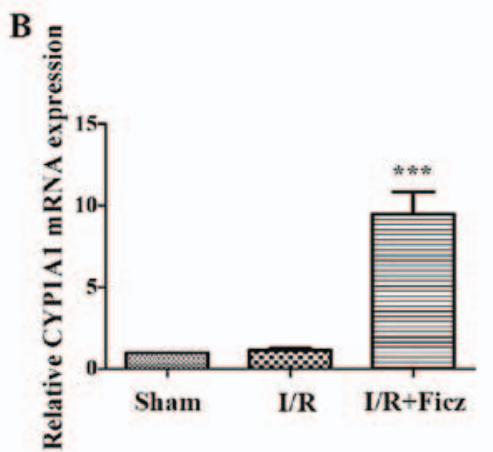
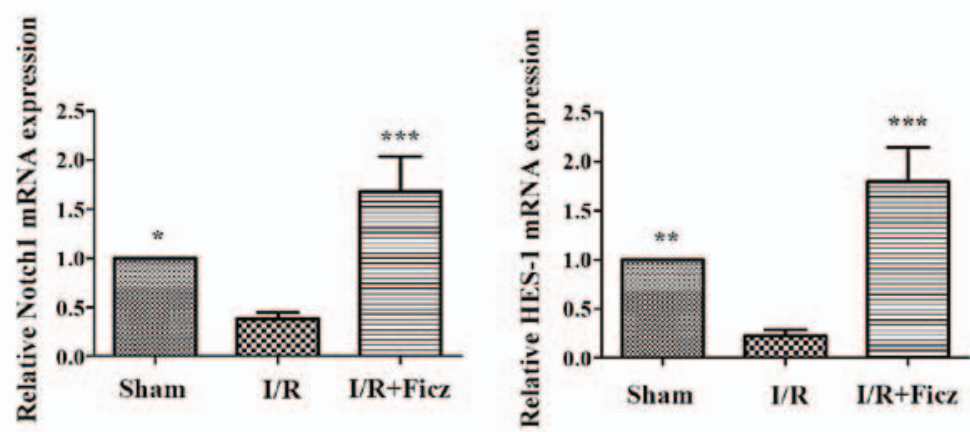

C

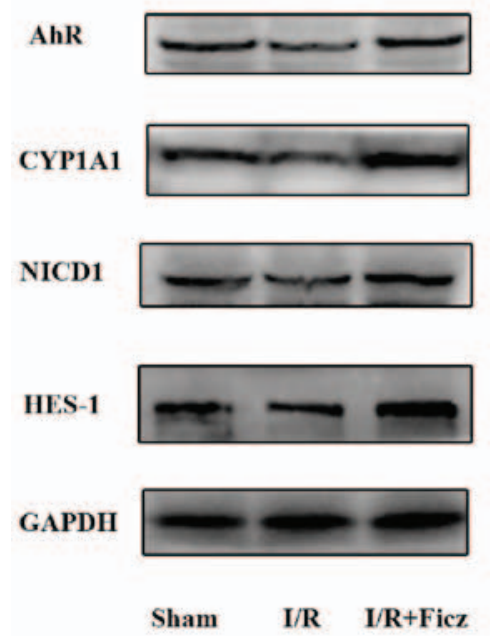

D

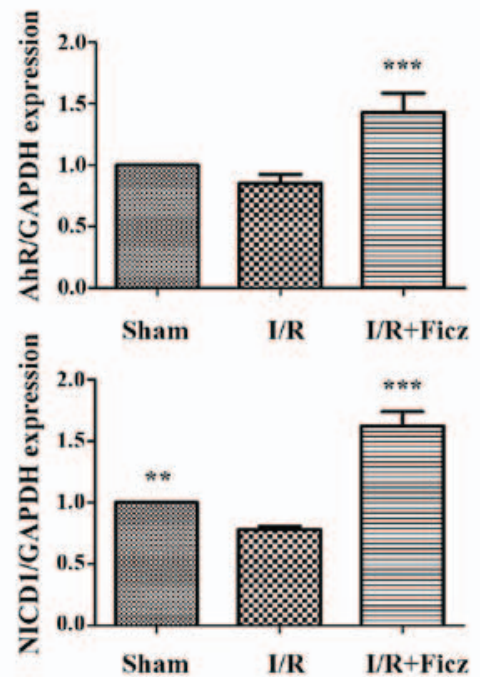

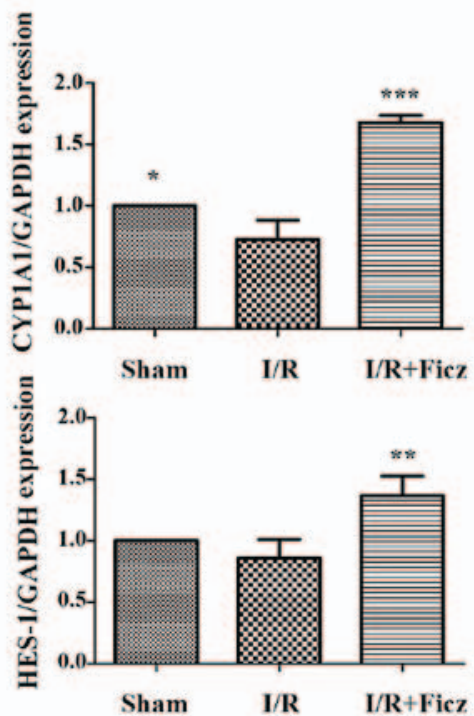

Figure 3. Ficz activates the epithelial AhR-Notch1 signaling pathway following intestinal I/R in mice. (A) AhR and Notch1 expression in sham, I/R and $\mathrm{I} / \mathrm{R}+$ Ficz groups detected by immunohistochemistry staining (original magnification, $\mathrm{x} 400$; scale bar, $25 \mu \mathrm{m} ; \mathrm{n}=3$ ). (B) Reverse transcription-quantitative polymerase chain reaction analysis of the mRNA levels of the CYP1A1, Notch1 and HES-1 in mice treated as in (A). (C) Western blotting of AhR, CYP1A1, NICD1, HES-1 and GAPDH protein levels. (D) Relative expressions of proteins determined by densitometry, GAPDH was used to verify equivalent loading. Data are presented as the mean \pm standard deviation. ${ }^{*} \mathrm{P}<0.05,{ }^{* *} \mathrm{P}<0.01,{ }^{* * * *} \mathrm{P}<0.001$ vs. I/R group; $\mathrm{n}=3$. I/R, ischemia/reperfusion; Ficz, 6-formylindolo(3,2-b) carbazole; AhR, aryl hydrocarbon receptor; NICD1, Notch1 intracellular domain; CYP1A1, cytochrome P450; HES-1, hes family bHLH transcription factor 1.

were used to determine the activity of Notch1 signaling. The results demonstrated that AhR and NICD1 were expressed in the nucleus and cytosol of intestinal epithelium and in the lamina propria (Fig. 3A). I/R in mice reduced the expression and activity of AhR-Notch1 signaling, while Ficz administration (1 $\mu \mathrm{g} / \mathrm{mouse})$ significantly upregulated the expression and activity of these signaling pathways, as indicated by the elevated AhR, CYP1A1, NICD1 and HES-1 mRNA and protein expression levels (Fig. 3B-D), which suggested that activation of AhR by Ficz upregulated epithelial Notch1 signaling following intestinal I/R in mice. 
A
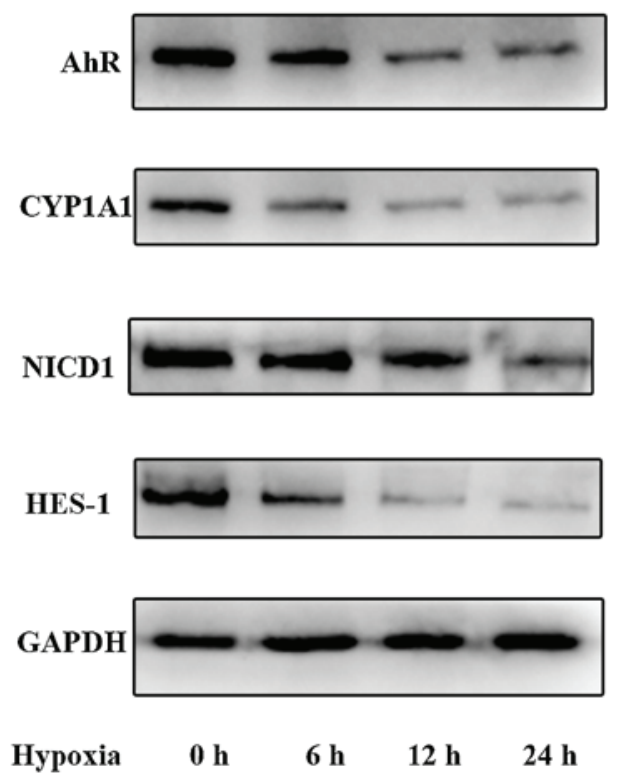

B
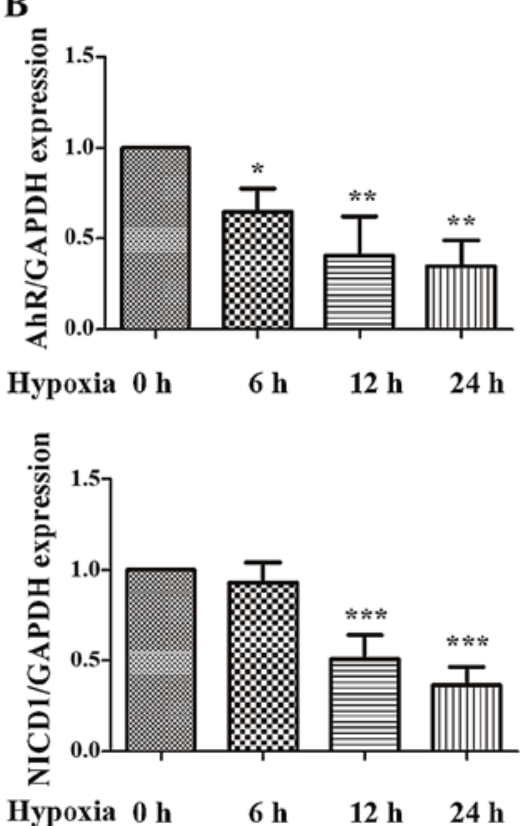
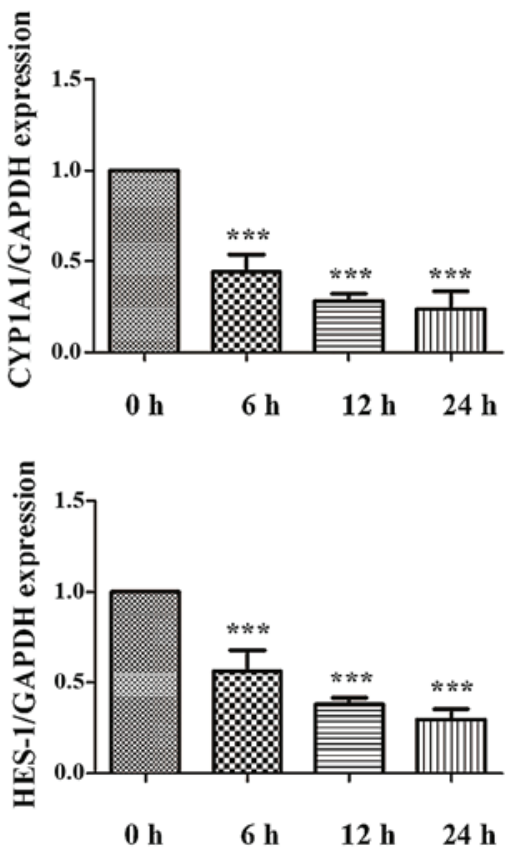

Figure 4. Effects of hypoxia on the expression and activity of AhR-Notch1 signaling pathway in Caco-2 monolayers. Caco-2 cells were subjected to hypoxic condition for 0, 6, 12 and 24 h. (A) Western blotting of AhR, CYP1A1, NICD1, HES-1 and GAPDH protein levels. (B) Relative expressions of proteins determined using desittometry. GAPDH was used to verify equivalent loading. Data are presented as mean \pm standard deviation. ${ }^{*} \mathrm{P}<0.05,{ }^{* *} \mathrm{P}<0.01,{ }^{* * * *} \mathrm{P}<0.001$ vs. hypoxia 0 h group; $n=3$. AhR, aryl hydrocarbon receptor; CYP1A1, cytochrome P450; NICD1, Notch1 intracellular domain; HES-1, hes family bHLH transcription factor 1

A
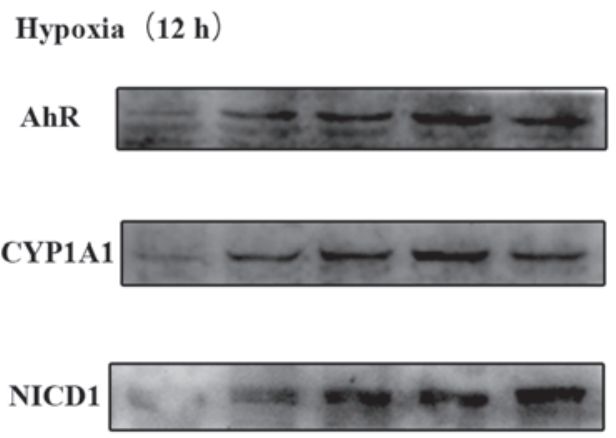

HES-1

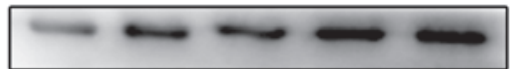

GAPDH

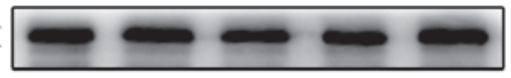

Ficz (nM)
B
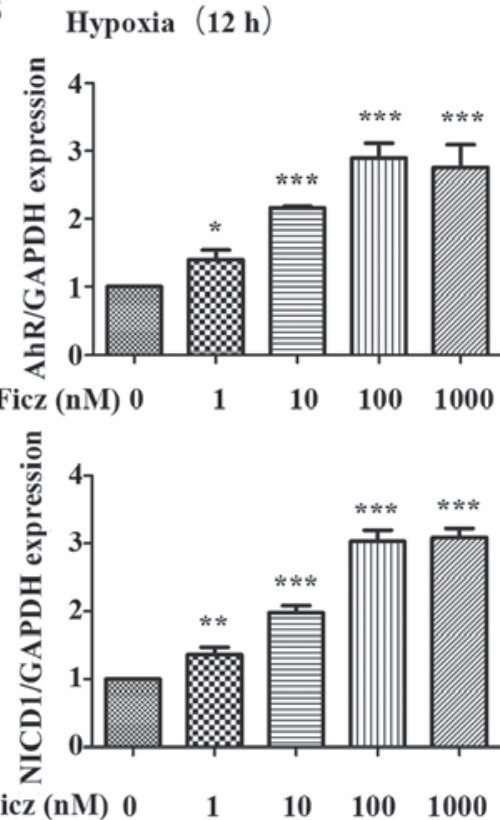
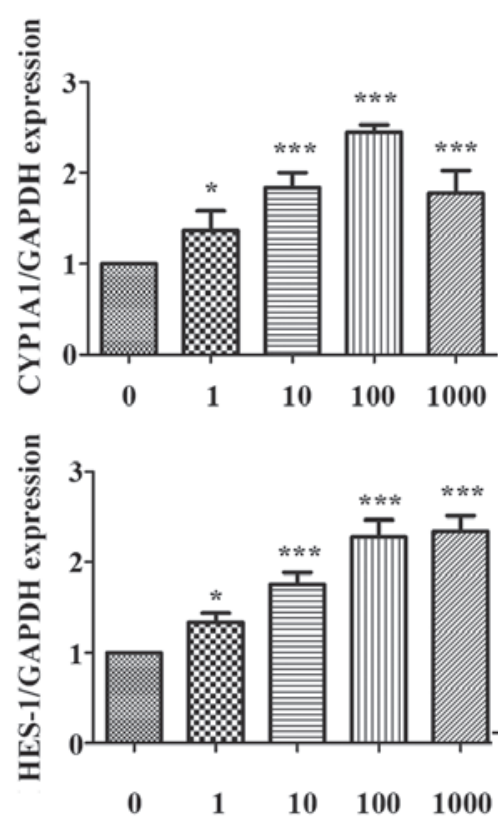

Figure 5. Effects of Ficz on the expression and activity of AhR-Notch1 signaling pathway in hypoxic Caco-2 cells. Caco-2 monolayers were administered with Ficz at five different concentrations $(0,1,10,100,1,000 \mathrm{nM})$ respectively and then exposed to hypoxia for $12 \mathrm{~h}$. (A) Western blotting of AhR, CYP1A1, NICD1, HES-1 and GAPDH protein levels. (B) Relative protein expressions determined by densitometry, GAPDH was used to verify equivalent loading. Data are presented as the mean \pm standard deviation. ${ }^{*} \mathrm{P}<0.05,{ }^{*} \mathrm{P}<0.01,{ }^{* * *} \mathrm{P}<0.001$ vs. Ficz $0 \mathrm{nM}$ group; $\mathrm{n}=3$. Ficz, 6 -formylindolo(3,2-b)carbazole; AhR, aryl hydrocarbon receptor; CYP1A1, cytochrome P450; NICD1, Notch1 intracellular domain; HES-1, hes family bHLH transcription factor 1.

AhR activation protects TJs against hypoxia-induced morphological destruction via upregulation of Notch1 signaling in Caco-2 monolayers. To further elucidate the underlying mechanism of the protective effects of AhR activation following I/R, Caco-2 cell lines were subjected to hypoxic conditions in vitro. As is demonstrated in Figs. 4 and 5, $12 \mathrm{~h}$ of hypoxia was optimal to mimic the in vivo I/R and the optimum concentration of Ficz to activate AhR-Notch1 signaling was $100 \mathrm{nM}$. Immunofluorescence demonstrated that AhR and NICD1 were expressed in the cytosol of the monolayers, and following 
A

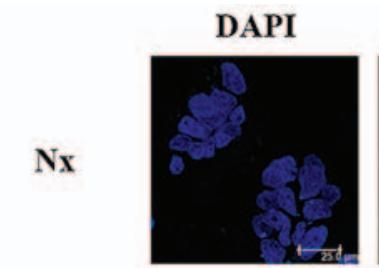

Nx+Ficz

(100 nM)
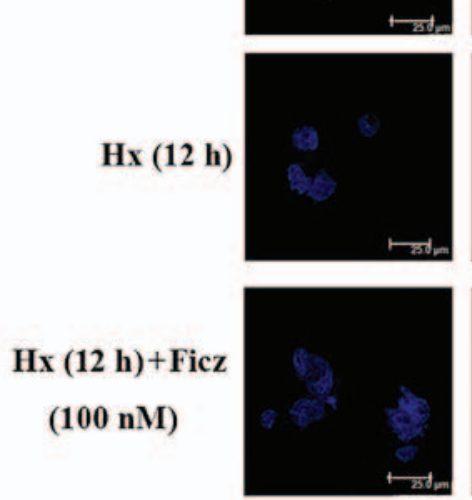

B

AhR
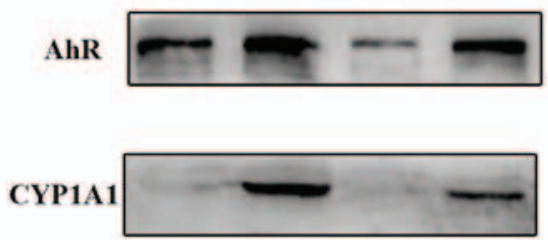

NICD1

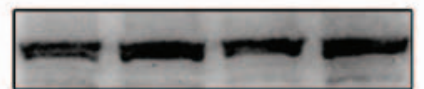

HES-1

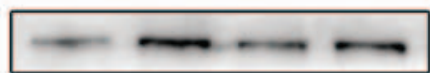

\section{GAPDH}
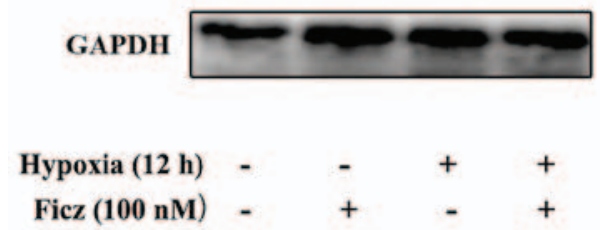

C
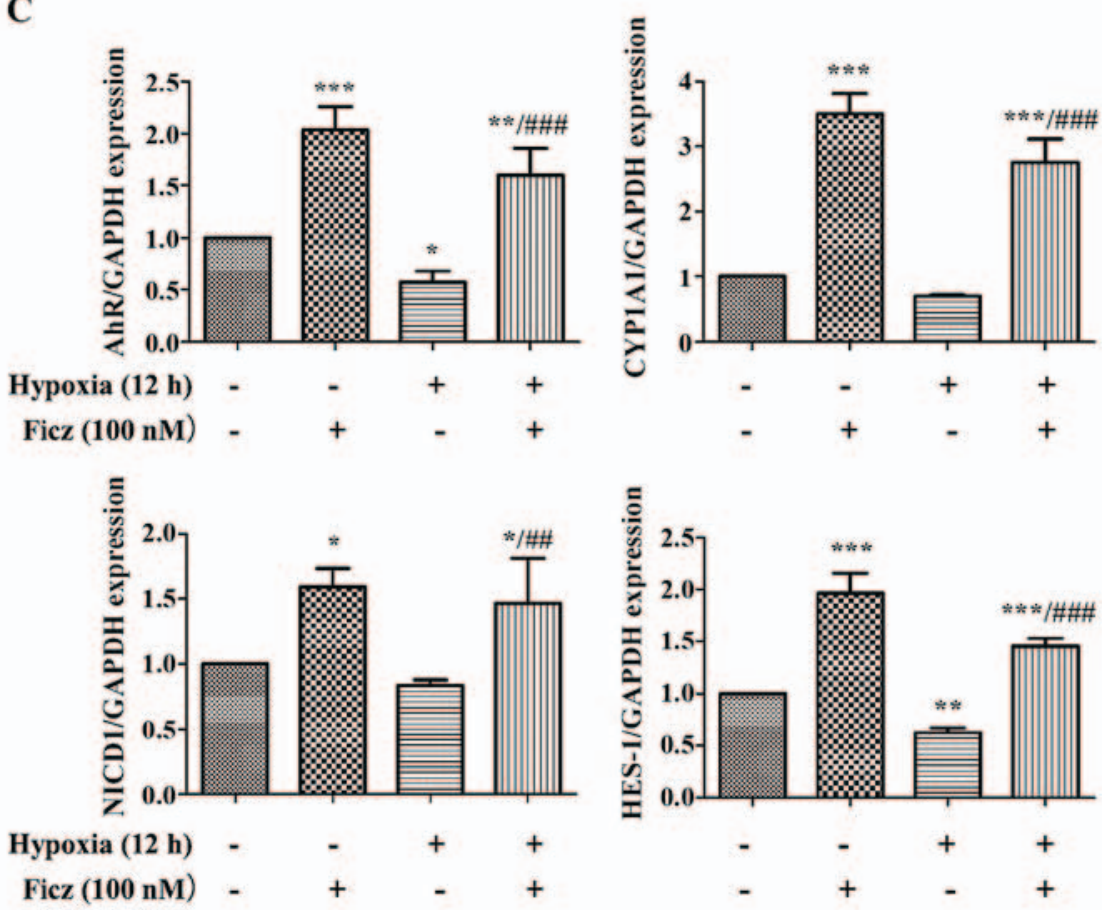
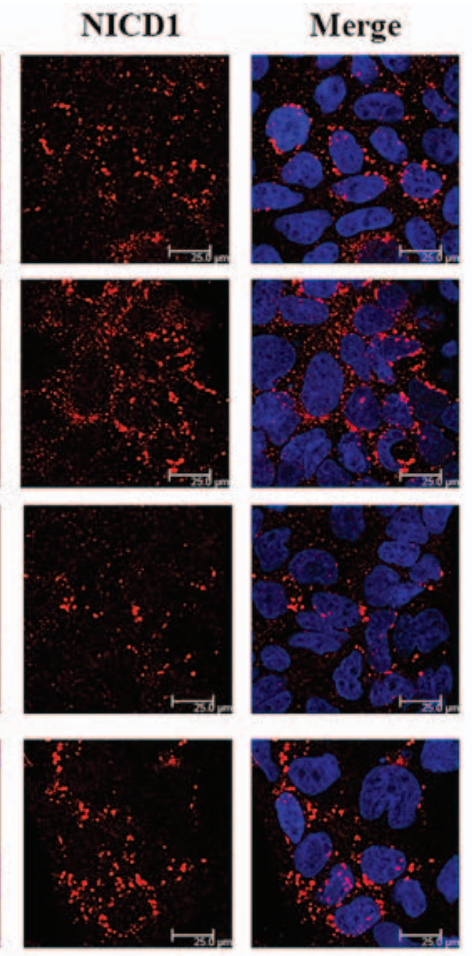

Figure 6. Ficz activates AhR-Notch1 signaling in Caco-2 cells under normoxic and hypoxic conditions. (A) Immunofluorescence staining was performed to evaluate the expression of AhR (green) and NICD1 (red) in four groups (Nx, Nx + Ficz, Hx and Hx + Ficz). Nuclei were counterstained with DAPI (blue; original magnification, $x 1,200$; scale bar, $25 \mu \mathrm{m}$; $\mathrm{n}=3$ ). (B) Western blotting was used to measure the protein levels of AhR, CYP1A1, NICD1, HES-1 and GAPDH. (C) Relative protein expressions determined by densitometry, GAPDH was used to verify equivalent loading. Data are presented as the mean \pm standard deviation. ${ }^{*} \mathrm{P}<0.05,{ }^{* *} \mathrm{P}<0.01,{ }^{* * * *} \mathrm{P}<0.001$ vs. Nx group; ${ }^{\# \#} \mathrm{P}<0.01,{ }^{\# \# \#} \mathrm{P}<0.001$ vs. Hx group; $=3$. AhR, aryl hydrocarbon receptor; NICD1, Notch1 intracellular domain; Nx, normoxia; Ficz, 6-formylindolo(3,2-b)carbazole; Hx, hypoxia; CYP1A1, cytochrome P450; HES-1, hes family bHLH transcription factor 1.

treatment with Ficz, the AhR and NICD1 appeared to have increased expression in the nuclei of the monolayers (Fig. 6A). Western blotting demonstrated that hypoxia downregulated the expression of AhR, NICD1, CYP1A1 and HES-1, while administration of Ficz significantly increased the expression of the proteins, and thus, activated AhR-Notch1 signaling under normoxic and hypoxic conditions (Fig. 6B and C). Immunofluorescence and western blotting were also performed to detect the formation and distribution of epithelial TJs (ZO-1 and occludin). ZO-1 and occludin were predominantly expressed on the membrane of the monolayers, however occludin was also detected in the cytoplasm (Fig. 7A). The 
A

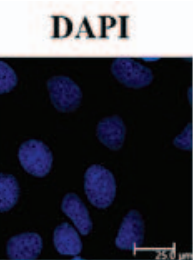

ZO-1
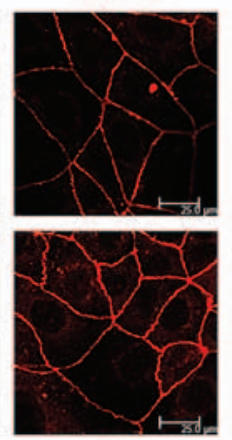

Hx (12 h)

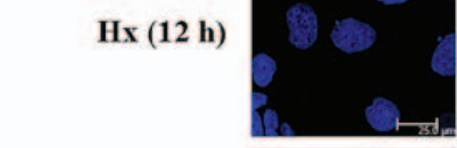

Hx (12 h) + Ficz

$(100 \mathrm{nM})$

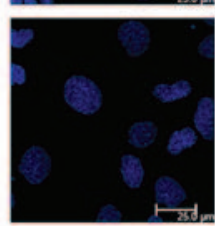

Merge
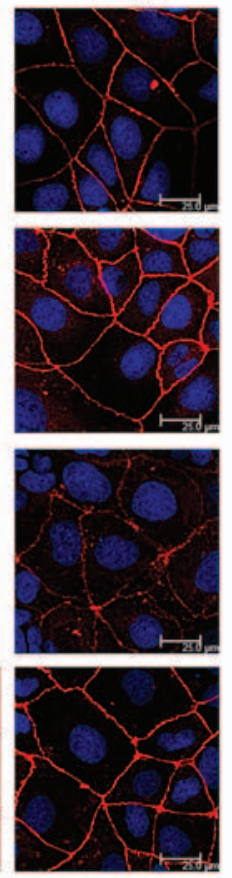

DAPI
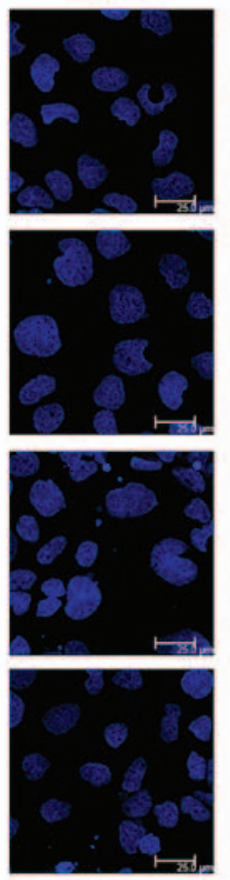

Occludin
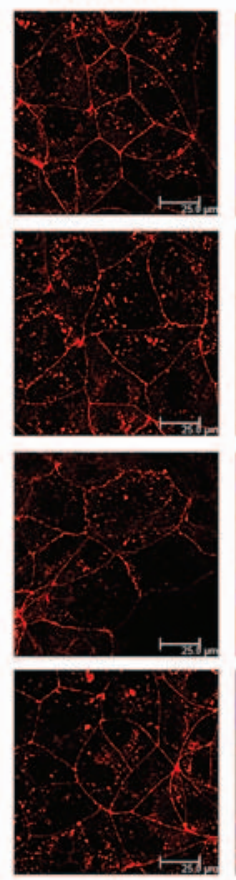

Merge
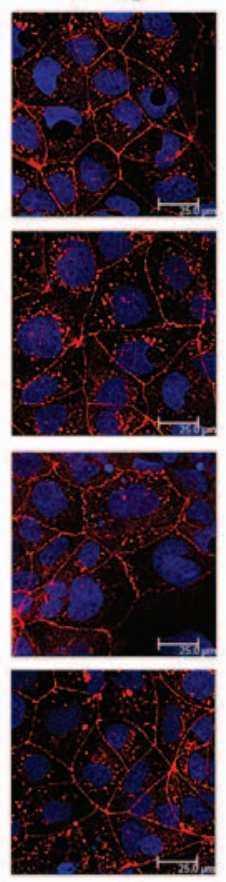

B
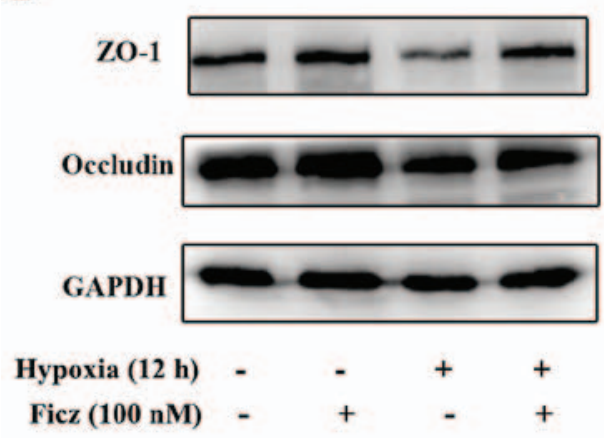

C
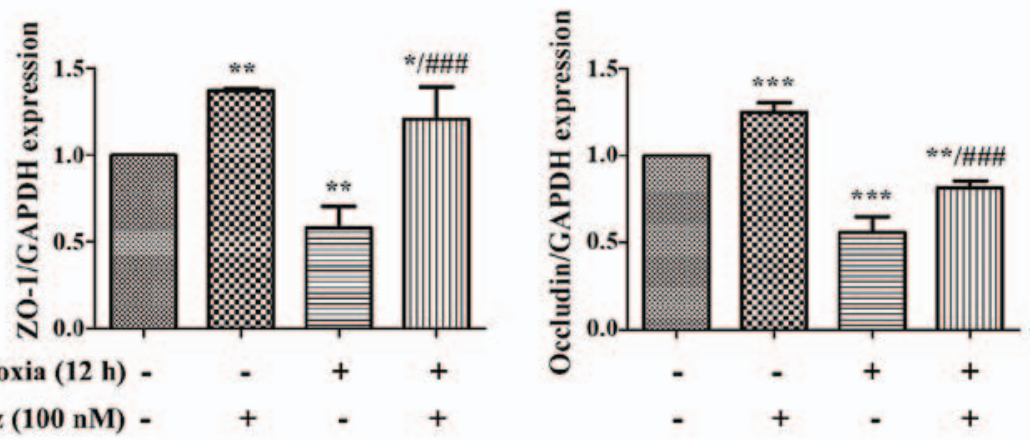

\section{D}

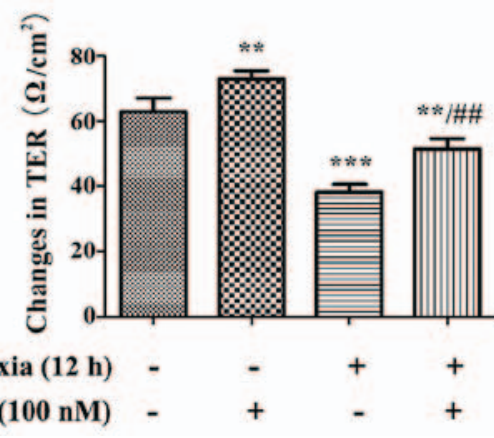

Figure 7. Ficz protects the tight junctions (ZO-1 and occludin) from hypoxia-induced morphological damage and maintains the barrier function in Caco-2 monolayers. (A) The expression and distribution of ZO-1 and occluldin (red) were detected by immunofluorescence staining in four groups (Nx, Nx + Ficz, $\mathrm{Hx}$ and $\mathrm{Hx}+$ Ficz). Nuclei were counterstained with DAPI (blue) (original magnification, $\mathrm{x} 1,200$; scale bar, $25 \mu \mathrm{m} ; \mathrm{n}=3$ ). (B) Western blotting was employed to investigate the protein expression of ZO-1, occludin and GAPDH. (C) Relative protein expressions determined by densitometry, GAPDH was used to verify equivalent loading. (D) The TER was detected by the Millipore electric resistance system to evaluate the epithelial permeability of Caco-2 cells in four groups. Data are presented as the mean \pm standard deviation. ${ }^{*} \mathrm{P}<0.05,{ }^{* *} \mathrm{P}<0.01,{ }^{* * *} \mathrm{P}<0.001$ vs. Nx group; ${ }^{\# \#} \mathrm{P}<0.01,{ }^{\# \# \#} \mathrm{P}<0.001$ vs. Hx group; $\mathrm{n}=3$. ZO-1, tight junction protein 1; Nx, normoxia; Ficz, 6-formylindolo(3,2-b)carbazole; Hx, hypoxia; TER, transepithelium electrical resistance.

data demonstrated that hypoxia reduced expression and disrupted the distribution of ZO-1 and occludin, whereas Ficz maintained their expression and distribution in Caco-2 monolayers under hypoxic conditions (Fig. 7B and C), in accordance with the in vivo experiments. TER was used to assess the endothelial barrier function. Compared with the normoxic condition $\left(62.67 \pm 4.41 \Omega / \mathrm{cm}^{2}\right)$, the TER of Caco-2 monolayers decreased markedly when exposed to hypoxic conditions $\left(38.20 \pm 2.39 \Omega / \mathrm{cm}^{2}\right)$, while administration of Ficz under hypoxic conditions restored the TER $\left(51.4 \pm 03.15 \Omega / \mathrm{cm}^{2}\right.$; 
A

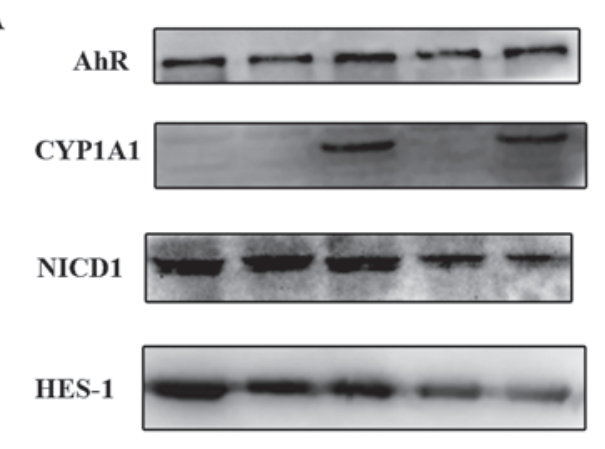

ZO-1

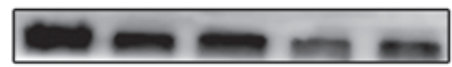

Occludin

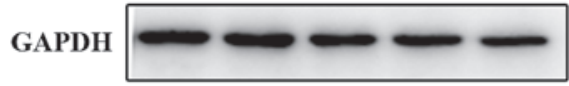

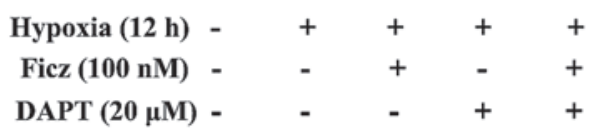

B

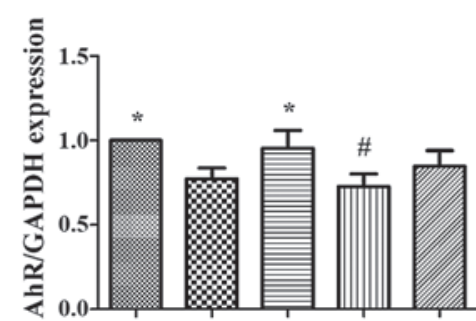

Hypoxia (12 h) - + + + +

Ficz $(100 \mathrm{nM})-\quad+\quad+-+$

DAPT $(20 \mu \mathrm{M})$ - $\quad-\quad-\quad++$

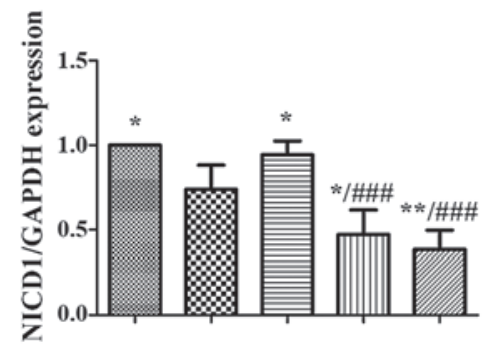

$\begin{array}{llllll}\text { Hypoxia }(12 \text { h) } & - & + & + & + & + \\ \text { Ficz }(100 \mathrm{nM}) & - & - & + & - & + \\ \text { DAPT }(20 \mu \mathrm{M}) & - & - & - & + & +\end{array}$

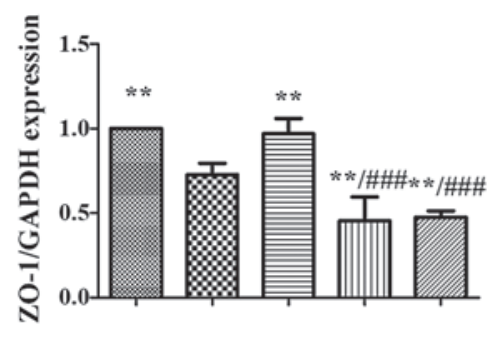

Hypoxia (12 h) - ++++

Ficz (100 nM) - - $+-\quad+$

DAPT $(20 \mu M)$ - $\quad-\quad-\quad+\quad+$
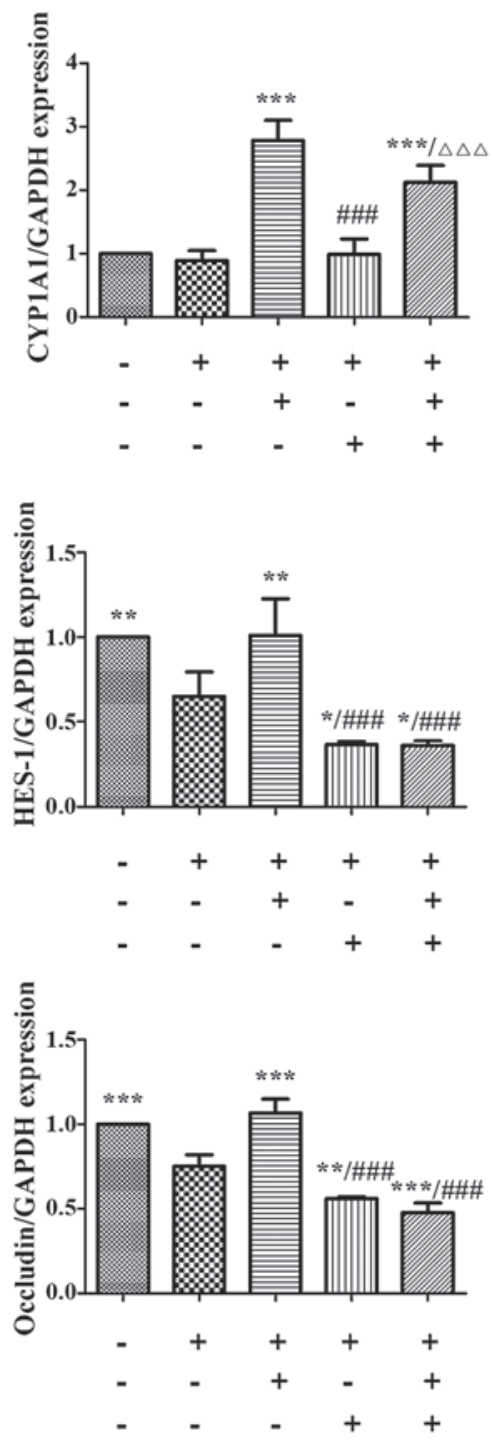

Figure 8. Blocking Notch1 signaling with DAPT obstructed the effects of Ficz on the development of tight junctions in hypoxic Caco-2 cells. (A) Western blottting was performed to assess the protein levels of aryl hydrocarbon receptor (AhR)-Notch1 signaling components and TJs (ZO-1 and occludin) in 5 groups (Nx, Hx, Hx + Ficz, Hx + DAPT and Hx + Ficz + DAPT). (B) Relative protein expressions determined by densitometry, GAPDH was used to verify equivalent loading. Data are presented as the mean \pm standard deviation. ${ }^{*} \mathrm{P}<0.05,{ }^{* *} \mathrm{P}<0.01,{ }^{* * * *} \mathrm{P}<0.001$ vs. Hx group; ${ }^{\# \# \#} \mathrm{P}<0.001$ vs. Hx + Ficz group; ${ }^{\Delta \Delta \Delta} \mathrm{P}<0.001$ vs. Hx+DAPT group; $\mathrm{n}=3$. AhR, aryl hydrocarbon receptor; NICD1, Notch1 intracellular domain; CYP1A1, cytochrome P450; HES-1, hes family bHLH transcription factor 1; ZO-1, tight junction protein 1; Ficz, 6-formylindolo(3,2-b)carbazole; DAPT, N-[N-(3,5-difluorophenacetyl)-L-alanyl]-S-phenylglycine t-butyl ester; Nx, normoxia; Hx, hypoxia.

Fig. 7D). Overall, activation of AhR by Ficz was confirmed to maintain the epithelial barrier function under hypoxic conditions and maintain ZO-1 and occludin expression/distribution by activation of Notch1 signaling in vitro.

Blocking Notchl signaling with DAPT counteracts the effects of Ficz on the development of TJs in hypoxic Caco-2 monolayers. To determine whether the upregulation of Notch1 signaling was the underlying mechanism of AhR activation in maintaining the endothelial barrier function in Caco-2 monolayers, $20 \mu \mathrm{M}$ DAPT, a $\gamma$-secretase inhibitor, was administrated to block the Notch1 signaling (31). The results demonstrated that, under hypoxic conditions, the AhR and CYP1A1 expression in Caco-2 monolayers were similar in the Hx + Ficz and Hx + Ficz + DAPT groups (Fig. 8A and B), suggesting that DAPT had no effect on the upstream AhR signaling. Additionally, the expression levels of NICD1 and HES-1 in the Hx + DAPT group were significantly decreased compared with the $\mathrm{Hx}+$ Ficz group, while the levels in the Hx + Ficz + DAPT group remained similar to the Hx + DAPT group, suggesting that the inhibitory effect of DAPT on Notch1 signaling was strong and cannot be altered by Ficz (Fig. 8A and B). As expected, the ZO-1 and occludin expression were not elevated by Ficz when combined with DAPT under hypoxic conditions (Fig. 8A and B), suggesting that the potential mechanism of AhR activation in the development of TJs in hypoxic Caco-2 cells is mediated by upregulation of Nocth1 signaling.

\section{Discussion}

Intestinal $\mathrm{I} / \mathrm{R}$ injury is a major clinical challenge that occurs in patients with severe trauma, midgut volvulus, mesenteric 
artery embolism, or following other vascular and abdominal surgeries $(1,32)$. The interruption of intestinal blood flow rapidly reduces tissue oxygenation, damages intestinal epithelium and increases mucosal permeability. Although the pathophysiological progression of intestinal I/R is well understood, currently, there is no efficient solution to solve this problem. In the present study, the potential effect of AhR activation by Ficz in modulating intestinal barrier function in a mouse model of intestinal I/R was investigated. The results demonstrated that activation of AhR by Ficz upregulated the Notch1 signaling pathway, maintained the intestinal histomorphology and osmotic balance and reversed the disrupted distribution of TJs following intestinal I/R in mice or hypoxia in Caco-2 monolayers. Furthermore, inhibition of Notch1 signaling by DAPT reversed the effects of Ficz on TJs in hypoxic Caco-2 cells. In this way, it is clear that upregulation of Notch1 signaling is the underlying mechanism by which AhR activation alleviates intestinal barrier dysfunction following I/R.

Ficz is an endogenous AhR ligand with higher affinity and lower toxicity than TCDD (33). To explore the underlying molecular mechanism, intraperitoneal administration of Ficz to activate AhR signaling in the mouse I/R model. Previous studies have demonstrated that $\mathrm{AhR}$ is downregulated in intestinal tissues of patients with inflammatory bowel disease. Activation of AhR by Ficz maintained the survival rate, body weight and development of histopathological lesions, downregulated proinflammatory cytokines and altered the intraepithelial lymphocyte phenotype in animal models of colitis induced by dextran sodium sulfate or trinitrobenzene sulfonic acid (11,12). Jing et al (16) also reported that the expression and activity of AhR were downregulated in rat liver tissues following intestinal I/R, while MG132 administration maintained the expression and activity of AhR and alleviated the liver injury under intestinal I/R conditions. These findings are in accordance with the results of the current study indicating that intestinal I/R reduced the expression and activity of AhR, while Ficz increased the expression and activity of AhR following intestinal I/R, suggesting that AhR signaling may be involved in the intestinal mucosal injury induced by $\mathrm{I} / \mathrm{R}$.

Encouraged by these findings, whether activation of AhR by Ficz had protective effects against intestinal I/R was also investigated. Histological examination was performed to estimate the effects of Ficz on the morphological changes following intestinal $\mathrm{I} / \mathrm{R}$. The results suggested that the intestinal morphological features arising from intestinal I/R were characterized by shortening of the villi, shedding of the epithelium, multiple erosions, immune cell infiltration, hemorrhage and necrosis. The results were consistent with previous studies on animal models of intestinal I/R $(6,34)$. The intestinal mucosal lesions induced by $\mathrm{I} / \mathrm{R}$ were more severe than those of the sham group, while Ficz markedly alleviated the intestinal mucosal lesions following intestinal I/R, which indicated that activation of AhR by Ficz could maintain the intestinal mucosal morphology in a mouse model of acute intestinal I/R.

AhR regulation of Notch signaling has been confirmed by numerous studies. Accumulating evidence has indicated that several AhREs are present in Notch1 gene promoters, and AhR ligands (TCDD, Ficz) upregulated their transcription in hepatocytes, ILCs and BMDCs (21-23). Alam et al (24) reported that Notch signaling induced endogenous stimulation of $\mathrm{AhR}$ in activated $\mathrm{CD} 4^{+} \mathrm{T}$ cells. Additionally, Notch signaling downregulated microRNA-223, which was identified as a negative regulator of the AhR/ARNT pathway (35). Considering these previous findings, the effects of AhR activation by Ficz on the expression and activity of epithelial Notch1 signaling following intestinal I/ $R$ in mice were investigated in the current study. Our previous study demonstrated that Notch1 signaling was activated at $2 \mathrm{~h}$ after intestinal I/R in rats, whereas after $6 \mathrm{~h}$ of reperfusion, the Notch 1 mRNA level and NICD1 protein level were decreased (20). This temporary activation of Notch1 signaling may due to the stress response induced by the early stage of I/R. Consistent with these findings, the results of the present study demonstrated that the expression of NICD1 and HES-1 decreased following intestinal I/R while AhR activation by Ficz significantly increased the expression of NICD1 and HES-1 following intestinal I/R, which confirmed that AhR activation by Ficz upregulated Notch1 signaling in intestinal epithelial cells following intestinal I/R.

TJs maintain IEB function by regulating the permeability to water, ions and nutrients (4). The alteration of the TJ function is dynamically regulated by various signaling pathways, including mitogen-activated proteinkinases, myosinlight-chain kinase and phosphoinositide 3-kinase/protein kinase B (36). However, Dahan et al (17) reported that activation of the epithelial Notch1 signaling pathway by $\mathrm{CD} 4^{+} \mathrm{T}$ cells adoptive transfer maintained claudin-5 expression in colonic tissues of recombination activating gene 1-null mice, and interference of Notch1 signaling in Caco-2 cells increased the expression of claudin-2, while occludin expression decreased. Mathern et al (18) also reported that in Notch1 small interfering RNA-treated mice, the expression of claudin-5 in colonic tissues was also significantly decreased. All these findings supported that Notch1 signaling may have a crucial role in maintaining the intestinal barrier function by regulating the development of TJ proteins. Additionally, Pope et al (37) demonstrated that upregulation of claudin-1 in colonic epithelium activated Notch1 signaling by increasing matrix metalloproteinase-9 and phospho-ERK signaling, this suggested that TJs and Notch1 signaling may have an interaction that maintains the intestinal barrier function. Movahedan et al (38) also reported that the ZO-1 formation is delayed in Notch1-null corneal epithelial cells in vitro. Thus, it was speculated whether activation of AhR-Notch1 signaling by Ficz alleviates the barrier dysfunction by maintaining the expression of TJ proteins and TJ architecture following intestinal I/R. The results of the current study demonstrated that the intestinal I/R caused disrupted expression and distribution of TJs (ZO-1 and occludin) and increased intestinal mucosal permeability, which was in accordance with our previous studies $(5,6)$. Ficz ameliorated the disruption of TJs and maintained the mucosal permeability following intestinal I/R. These results indicated that Ficz may have a vital role in the maintenance of the intestinal barrier function under I/R conditions, potentially mediated via the activation of AhR-Notch1 signaling.

A Caco-2 cell model of hypoxia (12 h) was used to mimic intestinal I/R and to explore the role of AhR activation in the 
regulation of endothelial barrier function in vitro. As with murine I/R, activated AhR maintained the epithelial barrier function and paracellular permeability under hypoxic conditions in Caco-2 cells through the recovery of TJs (ZO-1 and occludin). The results also demonstrated that activation of AhR by Ficz repressed the downregulation of Notch1 signaling induced by hypoxia. The activity of AhR-Notch1 signaling and TJ protein expression were detected in Caco-2 monolayers following treatment with DAPT, a blocker of Notch signaling. The data confirmed that, in hypoxic condition, blocking of Notch1 signaling with DAPT had marked effect on the expression and activity of AhR with or without Ficz. By contrast, loss of Notch1 counteracted the development of TJs (ZO-1 and occludin) induced by Ficz. Activated AhR was demonstrated to have an important role in epithelial barrier defense under hypoxic conditions, and the upregulation of the Notch1 signaling pathway has been demonstrated to be the potential molecular mechanism involved.

In conclusion, in the present study has provided novel insights into the protective role of $\mathrm{AhR}$ in regulation of intestinal barrier dysfunction induced by $\mathrm{I} / \mathrm{R}$ in vivo and in vitro. Activation of AhR may be a novel approach for the treatment of acute intestinal $\mathrm{I} / \mathrm{R}$ in the clinic.

\section{Acknowledgements}

This study was supported by grants from the National Natural Science Foundation of China (grant no. NSFC 81330013 to H.Y., grant no. NSFC 81300275 to L.H.S, grant no. NSFC 81270451 to W.D.X. and grant no. NSFC 81501661 to M.Y), and the Program of Changjiang Scholars and Innovative Research (grant no. IRT 13050 to HY).

\section{References}

1. Arda-Pirincci P and Bolkent S: The role of epidermal growth factor in prevention of oxidative injury and apoptosis induced by intestinal ischemia/reperfusion in rats. Acta Histochem 116 : 167-175, 2014.

2. Granger DN and Korthuis RJ: Physiologic mechanisms of postischemic tissue injury. Annu Rev Physiol 57: 311-332, 1995.

3. Matthijsen RA, Derikx JP, Kuipers D, van Dam RM, Dejong CH and Buurman WA: Enterocyte shedding and epithelial lining repair following ischemia of the human small intestine attenuate inflammation. PLoS One 4: e7045, 2009.

4. Lee SH: Intestinal permeability regulation by tight junction: implication on inflammatory bowel diseases. Intest Res 13: 11-18, 2015.

5. Yang Y, Qiu Y, Wang W, Xiao W, Liang H, Zhang C, Yang H, Teitelbaum DH, Sun LH and Yang H: Adenosine A2B receptor modulates intestinal barrier function under hypoxic and ischemia/reperfusion conditions. Int J Clin Exp Pathol 7: 2006-2018, 2014.

6. Cai Y, Wang W, Liang H, Sun L, Teitelbaum DH and Yang H: Keratinocyte growth factor improves epithelial structure and function in a mouse model of intestinal ischemia/reperfusion. PLoS One 7: e44772, 2012.

7. Xie G, Peng Z and Raufman JP: Src-mediated aryl hydrocarbon and epidermal growth factor receptor cross talk stimulates colon cancer cell proliferation. Am J Physiol Gastrointest Liver Physiol 302: G1006-G1015, 2012.

8. Marlowe JL, Fan Y, Chang X, Peng L, Knudsen ES, Xia Y and Puga A: The aryl hydrocarbon receptor binds to E2F1 and inhibits E2F1-induced apoptosis. Mol Biol Cell 19: 3263-3271, 2008.

9. Mandavia C: TCDD-induced activation of aryl hydrocarbon receptor regulates the skin stem cell population. Med Hypotheses 84: 204-208, 2015.

10. Qiu J, Heller JJ, Guo X, Chen ZM, Fish K, Fu YX and Zhou L: The aryl hydrocarbon receptor regulates gut immunity through modulation of innate lymphoid cells. Immunity 36: 92-104, 2012.
11. Monteleone I, Rizzo A, Sarra M, Sica G, Sileri P, Biancone L, MacDonald TT, Pallone F and Monteleone G: Aryl hydrocarbon receptor-induced signals up-regulate IL-22 production and inhibit inflammation in the gastrointestinal tract. Gastroenterology 141: 237-248, 2011.

12. Ji T, Xu C, Sun L, Yu M, Peng K, Qiu Y, Xiao W and Yang H: Aryl hydrocarbon receptor activation down-regulates IL-7 and reduces inflammation in a mouse model of DSS-induced colitis. Dig Dis Sci 60: 1958-1966, 2015.

13. Qiu J, Guo X, Chen ZM, He L, Sonnenberg GF, Artis D, Fu YX and Zhou L: Group 3 innate lymphoid cells inhibit T-cell-mediated intestinal inflammation through aryl hydrocarbon receptor signaling and regulation of microflora. Immunity 39: 386-399, 2013.

14. Arsenescu R, Arsenescu V, Zhong J, Nasser M, Melinte R, Dingle RW, Swanson H and de Villiers WJ: Role of the xenobiotic receptor in inflammatory bowel disease. Inflamm Bowel Dis 17: 1149-1162, 2011.

15. Li Y, Innocentin S, Withers DR, Roberts NA, Gallagher AR, Grigorieva EF, Wilhelm C and Veldhoen M: Exogenous stimuli maintain intraepithelial lymphocytes via aryl hydrocarbon receptor activation. Cell 147: 629-640, 2011.

16. Jing H, Shen G, Wang G, Zhang F, Li Y, Luo F, Yao J and Tian XF: MG132 alleviates liver injury induced by intestinal ischemia/reperfusion in rats: involvement of the AhR and NFKB pathways. J Surg Res 176: 63-73, 2012.

17. Dahan S, Rabinowitz KM, Martin AP, Berin MC, Unkeless JC and Mayer L: Notch-1 signaling regulates intestinal epithelial barrier function, through interaction with $\mathrm{CD} 4^{+} \mathrm{T}$ cells, in mice and humans. Gastroenterology 140: 550-559, 2011

18. Mathern DR, Laitman LE, Hovhannisyan Z, Dunkin D, Farsio S, Malik TJ, Roda G, Chitre A, Iuga AC, Yeretssian G, et al: Mouse and human Notch-1 regulate mucosal immune responses. Mucosal Immunol 7: 995-1005, 2014.

19. Chen G, Sun L, Yu M, Meng D, Wang W, Yang Y and Yang H: The Jagged-1/Notch-1/Hes-1 pathway is involved in intestinal adaptation in a massive small bowel resection rat model. Dig Dis Sci 58: 2478-2486, 2013.

20. Chen G, Qiu Y, Sun L, Yu M, Wang W, Xiao W, Yang Y, Liu Y, Yang S, Teitelbaum DH, et al: The jagged-2/notch-1/hes-1 pathway is involved in intestinal epithelium regeneration after intestinal ischemia-reperfusion injury. PLoS One 8: e76274, 2013.

21. Lee JS, Cella M, McDonald KG, Garlanda C, Kennedy GD, Nukaya M, Mantovani A, Kopan R, Bradfield CA, Newberry RD, et al: AHR drives the development of gut ILC22 cells and postnatal lymphoid tissues via pathways dependent on and independent of Notch. Nat Immunol 13: 144-151, 2011.

22. Stevens EA, Mezrich JD and Bradfield CA: The aryl hydrocarbon receptor: a perspective on potential roles in the immune system. Immunology 127: 299-311, 2009.

23. Xia M, Viera-Hutchins L, Garcia-Lloret M, Noval Rivas M, Wise P, McGhee SA, Chatila ZK, Daher N, Sioutas C and Chatila TA: Vehicular exhaust particles promote allergic airway inflammation through an aryl hydrocarbon receptor-Notch signaling cascade. J Allergy Clin Immunol 136: 441-453, 2015.

24. Alam MS, Maekawa Y, Kitamura A, Tanigaki K, Yoshimoto T, Kishihara K and Yasutomo K: Notch signaling drives IL-22 secretion in $\mathrm{CD}^{+} \mathrm{T}$ cells by stimulating the aryl hydrocarbon receptor. Proc Natl Acad Sci USA 107: 5943-5948, 2010.

25. Qiu Y, Yu M, Yang Y, Sheng H, Wang W, Sun L, Chen G, Liu Y, Xiao W and Yang H: Disturbance of intraepithelial lymphocytes in a murine model of acute intestinal ischemia/reperfusion. $\mathrm{J} \mathrm{Mol}$ Histol 45: 217-227, 2014

26. Chiu CJ, McArdle AH, Brown R, Scott HJ and Gurd FN: Intestinal mucosal lesion in low-flow states. I. A morphological, hemodynamic, and metabolic reappraisal. Arch Surg 101: 478-483, 1970.

27. Polentarutti BI, Peterson AL, Sjöberg AK, Anderberg EK, Utter LM and Ungell AL: Evaluation of viability of excised rat intestinal segments in the Ussing chamber: investigation of morphology, electrical parameters, and permeability characteristics. Pharm Res 16: 446-454, 1999.

28. Livak KJ and Schmittgen TD: Analysis of relative gene expression data using real-time quantitative PCR and the 2(-Delta Delta C(T)) Method. Methods 25: 402-408, 2001.

29. Nebert DW and Roe AL: Role of the aromatic hydrocarbon receptor and $[\mathrm{Ah}]$ gene battery in the oxidative stress response, cell cycle control, and apoptosis. Biochem. Pharmacol 59: 65-85, 2000 . 
30. Delescluse C, Lemaire G, de Sousa G and Rahmani R: Is CYP1A1 induction always related to AHR signaling pathway? Toxicology 153: 73-82, 2000

31. Chen G, Zhang Z, Cheng Y, Xiao W, Qiu Y, Yu M, Sun L, Wang W, Du G, Gu Y, et al: The canonical Notch signaling was involved in the regulation of intestinal epithelial cells apoptosis after intestinal ischemia/reperfusion injury. Int J Mol Sci 15: 7883-7896, 2014

32. Huang CY, Hsiao JK, Lu YZ, Lee TC and Yu LC: Anti-apoptotic $\mathrm{PI} 3 \mathrm{~K} / \mathrm{Akt}$ signaling by sodium/glucose transporter 1 reduces epithelial barrier damage and bacterial translocation in intestinal ischemia. Lab Invest 91: 294-309, 2011.

33. Jönsson ME, Franks DG, Woodin BR, Jenny MJ, Garrick RA, Behrendt L, Hahn ME and Stegeman JJ: The tryptophan photoproduct 6-formylindolo[3,2-b]carbazole (FICZ) binds multiple AHRs and induces multiple $C Y P 1$ genes via AHR2 in zebrafish. Chem Biol Interact 181: 447-454, 2009.

34. Daniel RA, Cardoso VK, Góis Jr E, Parra RS, Garcia SB, Rocha JJ and Féres O: Effect of hyperbaric oxygen therapy on the intestinal ischemia reperfusion injury. Acta Cir Bras 26: 463-469, 2011.

35. Ogando J, Tardáguila M, Díaz-Alderete A, Usategui A Miranda-Ramos V, Martínez-Herrera DJ, de la Fuente L, García-León MJ, Moreno MC, Escudero S, et al: Notch-regulated miR-223 targets the aryl hydrocarbon receptor pathway and increases cytokine production in macrophages from rheumatoid arthritis patients. Sci Rep 6: 20223, 2016.
36. González-Mariscal L, Tapia R and Chamorro D: Crosstalk of tight junction components with signaling pathways. Biochim Biophys Acta 1778: 729-756, 2008.

37. Pope JL, Bhat AA, Sharma A, Ahmad R, Krishnan M, Washington MK, Beauchamp RD, Singh AB and Dhawan P: Claudin-1 regulates intestinal epithelial homeostasis through the modulation of Notch-signalling. Gut 63: 622-634, 2014.

38. Movahedan A, Afsharkhamseh N, Sagha HM, Shah JR, Milani BY, Milani FY, Logothetis HD, Chan CC and Djalilian AR: Loss of Notch1 disrupts the barrier repair in the corneal epithelium. PLoS One 8: e69113, 2013.

This work is licensed under a Creative Commons Attribution-NonCommercial-NoDerivatives 4.0 International (CC BY-NC-ND 4.0) License. 